\title{
LOGÍSTICA REVERSA NO SETOR PÚBLICO: PERCEPÇÃO E ANÁLISE DO PROCESSO APLICADO PELOS GESTORES AMBIENTAIS DO MUNICÍPIO DE CORRENTE-PI
}

Reverse logistics in the public sector: perception and analysis of applied process for environmental managers

$$
\text { at Corrente - PI }
$$

\section{Francisco Atualpa Ribeiro Filho ${ }^{1}$ Roselis Ribeiro B. Machado ${ }^{2}$}

\begin{abstract}
RESUMO: Apesar de aperfeiçoar técnicas e contribuir para o desenvolvimento, o uso de tecnologias cada vez mais aprimoradas faz com que certos produtos se tornem obsoletos. E então, nos encontramos sufocados em meio a tantos objetos que não tem mais funcionalidade e os descartamos. Para isso, materiais como pilhas, eletrônicos e pneus devem passar por um processo de reversibilidade, onde os fabricantes se responsabilizam pela sua coleta e destinação correta. O uso da logística reversa reduz a quantidade de resíduos que serão coletados e assim, diminui consequentemente, a quantidade a ser depositada em aterros municipais. Com a presente pesquisa, objetivou-se identificar as contribuições da logística reversa no setor público para redução dos custos e minimização dos impactos ambientais tendo como universo a cidade interiorana de Corrente, localizada no sul do estado do Piauí. A metodologia empregada consistiu em um estudo de revisão bibliográfica detalhada e visitas in loco para levantamento de dados. Os resultados encontrados justificaram a atual situação em que a cidade se encontra.
\end{abstract}

PALAVRAS-CHAVE: Logística Reversa; Reversibilidade; Piauí; Corrente.

ABSTRACT: Although techniques enhance and contribute to the development, the use of increasingly refined technologies makes certain products become obsolete. And then we find ourselves suffocated amid so many objects that do not have more functionality and discard. For this, materials such as batteries, electronics and tires must undergo a reversible process where manufacturers are responsible for their collection and proper disposal. The use of the reverse logistic reduces the amount of waste to be collected and thus decreases consequently, the amount to be deposited in municipal landfills. With this research aimed to identify the contributions of reverse logistic in the public sector to reduce costs and minimize environmental impacts like having the universe city inland Corrente, located in the south of Piauí state. The methodology

\footnotetext{
${ }^{1}$ Pós-graduando do Programa Nacional de Formação de Administradores Públicos (PNAP) - Especialização em Gestão Pública Municipal NEAD/UESPI - Campus Corrente - PI, e-mail: atuorgines25@hotmail.com. Licenciado em Filosofia pela Mackenzie-SP; Bacharelando do V período de Administração Pública - UESPI

2 Professora Doutora Orientadora, Adjunta III da Universidade Estadual do Piauí - Centro de Ciências da Natureza.
} 
employed consisted of a detailed study of literature review and in situ visits for data collection. The results found justified the current situation where the city is.

KEYWORDS: Reverse Logistic; Reversibility; Piauí; Corrente.

\section{INTRODUÇÃO}

Em meio ao desenvolvimento tecnológico atual, a utilidade de um produto não determina que o cliente use-o até este tornar-se obsoleto. Com isso, a obsolescência programada - que persiste no meio social e impregna os lares brasileiros - remete-se a uma problemática que tende a saltar dos olhos da população: o crescente acúmulo de resíduos sólidos.

A problemática imposta pela destinação final destes resíduos vem participando, a cada dia mais, de parte da preocupação diária dos cidadãos. A precariedade de algumas regiões faz com que a coleta seja por muitas vezes, má organizada e sua destinação imprópria. Materiais distintos são armazenados e destinados todos juntos, sem que se tenha o cuidado de separá-los, ou nem mesmo utilizam a prática da incineração de rejeitos hospitalares, por exemplo. Materiais radioativos e eletrônicos, que não deveriam ser alocados junto a outros, são expostos no meio ambiente indevidamente.

Assim, surge um processo inovador de destinação. Caracterizado por um conjunto de procedimentos que viabilizam a coleta do resíduo e sua restituição, a logística reversa é tida também como uma técnica de desenvolvimento econômico, ao mesmo tempo em que é um instrumento social. Isso porque, essa reversibilidade de materiais e seus incentivadores tentam promover a conscientização (social) e, de certo modo, o destino seguro ou até mesmo a reutilização dos resíduos sólidos como geração de renda (econômico).

Daher et al. (2004), relata que "a logística reversa em seu sentido mais amplo, significa todas as operações relacionadas com a reutilização de produtos e materiais." Então, refere-se às atividades logísticas de coletar, separar e processar produtos e/ou materiais e peças usados a fim de ter uma recuperação sustentável antes do descarte dos componentes inutilizáveis no meio ambiente.

Em termos gerais, observando a posição das empresas que realizam essa atividade, definese que: 
Logística é o processo de gerenciar estrategicamente a aquisição, movimentação e armazenamento de materiais, peças e produtos acabados, sua organização e dos seus canais de distribuição de modo a poder maximizar a lucratividade da empresa e o atendimento e satisfação dos clientes a baixo custo. (GUARNIERI ${ }^{3}$ ).

Com isso, LEITE $^{4}$ endossa a perspectiva de Guarnieri pontuando o seguinte a respeito da logística reversa:

\begin{abstract}
A logística reversa é um ramo da logística empresarial que planeja, opera e controla o fluxo e as informações logísticas correspondentes, do retorno dos bens de pós-venda e de pós-consumo ao ciclo de negócios ou ao ciclo produtivo, por meio dos canais de distribuições reversos, agregando-lhes valor de diversas naturezas: econômico, ecológico, legal, logístico, de imagem corporativa, entre outros.
\end{abstract}

Desse modo, a logística usada tradicionalmente de alocação, coleta, e deposição final, de nada tem a ver com a reversa. Pois, elas se diferem num quesito: na reversa, é realizado o processo ao contrário (reverso), de modo que o produto tóxico, por exemplo, seja reaproveitado por meio da reciclagem.

Não obstante, um maior interesse pela consciência ambiental da indústria tem sido observado devido ao aumento da poluição, desenvolvimento de legislações preventivas e o crescimento da demanda de produtos e processos de produção 'verde' estão em constante mudança, pois a logística reversa constitui uma poderosa ferramenta que se bem aplicada poderse-ia ser uma contribuição generosa ao planeta.

Tendo em vista o desperdício, a periculosidade e também, a toxidade de alguns resíduos sólidos alocados indevidamente junto a rejeitos e materiais diversos, optou-se pelo estudo aprofundado desta temática.

O presente artigo teve fundamentação com a Política Nacional de Resíduos Sólidos (PNRS), instituída pela Lei $\mathrm{n}^{\circ}$ 12.305, de 2 de agosto de 2010 sendo regulamentada pelo Decreto $\mathrm{n}^{\mathrm{o}} 7.404$ de 23 de dezembro de $2010^{5}$ cuja qual defende a reversibilidade de materiais e conceitua dessa forma:

Art. 3, XII: Logística reversa: instrumento de desenvolvimento econômico e social caracterizado por um conjunto de ações, procedimentos e meios destinados a viabilizar a coleta e a restituição dos resíduos sólidos ao setor empresarial, para reaproveitamento, em seu ciclo ou em outros ciclos produtivos, ou outra destinação final ambientalmente adequada.

\footnotetext{
3 GUARNIERI, P. Logística Reversa: em busca do equilíbrio econômico e ambiental. Recife: Clube de Autores, 2011. p. 32.

${ }^{4}$ LEITE, P. R. Logística Reversa: Meio Ambiente e Competitividade. São Paulo: Pearson Prentice Hall, 2003. p. 16.

5 BRASIL. Lei $\mathrm{n}^{\circ}$ 12.305, de 2 de agosto de 2010. Institui a Política Nacional de Resíduos Sólidos; altera a Lei $\mathrm{n}^{\circ}$ 9.605, de 12 de fevereiro de 1988; e dá outras providências. Lex: Diário Oficial [da] República Federativa do Brasil. Brasília, DF, 2010. http://www.planalto.gov.br/ccivil_03/_ato2007-2010/2010/lei/112305.htm. (último acesso em: 30/04/2015).
} 
Nesta, apesar de não fazer referência aos materiais radioativos (pois estes possuem legislação específica), cita sobre a obrigatoriedade desse processo e seus respectivos resíduos:

\begin{abstract}
Art. 33. São obrigados a estruturar e implementar sistemas de logística reversa, mediante retorno dos produtos após o uso pelo consumidor, de forma independente do serviço público de limpeza urbana e de manejo dos resíduos sólidos, os fabricantes, importadores, distribuidores e comerciantes de: I - agrotóxicos, seus resíduos e embalagens, assim como outros produtos cuja embalagem, após o uso, constitua resíduo perigoso, observadas as regras de gerenciamento de resíduos perigosos previstas em lei ou regulamento, em normas estabelecidas pelos órgãos do Sisnama, do SNVS e do Suasa, ou em normas técnicas; II - pilhas e baterias; III - pneus; IV - óleos lubrificantes, seus resíduos e embalagens; $\mathrm{V}$ - lâmpadas fluorescentes, de vapor de sódio e mercúrio e de luz mista; VI - produtos eletroeletrônicos e seus componentes. (BRASIL ${ }^{6}$.
\end{abstract}

Nesse sentido, pode-se salientar que, o trabalho que ora é apresentado irá coadunar em analisar os mecanismos que a secretaria de Meio Ambiente e Recursos Renováveis da cidade de Corrente, extremo sul do Piauí, está utilizando para sanar essa problemática ambiental regional, ao considerá-la em âmbito global.

A cidade de Corrente-PI, assim como qualquer outra, produz diariamente uma grande quantidade de resíduos descartados pela sua população. Dentre estes, encontram-se objetos como pilhas e aparelhos eletrônicos, cujos quais são o ponto chave para a existência de uma política de reversibilidade local.

Portanto, torna-se importante a busca de informações a respeito da utilização de meios como a logística reversa para devolução destes resíduos ao meio. Além de diferencial competitivo em atrair e manter clientes, a organização que faz uso desse processo desenvolve uma imagem positiva na população, já que prioriza atitudes consideradas sustentáveis.

O objetivo da presente pesquisa foi identificar as contribuições da logística reversa no setor público para redução dos custos e minimização dos impactos ambientais no município de Corrente, Piauí. Elucidando como ponto principal, a logística reversa como meio de desenvolvimento econômico e social, por meio da identificação de como a gestão municipal tem realizado a coleta e restituição dos resíduos sólidos no setor público, no que se refere ao reaproveitamento, em seu ciclo ou em outros ciclos produtivos, ou sua destinação. E, sugeriu-se ainda, mecanismos de aplicação do conhecimento adquirido para fomentar a participação social como instrumento preferencial para a implantação da logística reversa no município.

\title{
METODOLOGIA
}

${ }^{6}$ BRASIL. Lei ${ }^{\circ}$ 12.305, de 2 de agosto de 2010. Institui a Política Nacional de Resíduos Sólidos; altera a Lei ${ }^{\circ}$ 9.605, de 12 de fevereiro de 1988; e dá outras providências. Lex: Diário Oficial [da] República Federativa do Brasil. Brasília, DF, 2010. http://www.planalto.gov.br/ccivil_03/_ato2007-2010/2010/lei/112305.htm. (último acesso em: 30/04/2015). 


\section{Área de estudo}

O universo a ser estudado foi a cidade Corrente, sul do estado do Piauí. Conforme o Instituto Brasileiro de Geografia e Estatísticas (IBGE, 2014), o município possui 26.011 habitantes, distribuídos em um território de $3.048,446 \mathrm{~km}^{2}$ de extensão.

Como subáreas temos a Secretaria de Meio Ambiente e Recursos Renováveis, localizada na Prefeitura Municipal de Corrente, no bairro Nova Corrente. E também, o vazadouro à céu aberto da região que supre as necessidades tanto das áreas urbanas quanto rurais do município. Este está localizado na zona rural do município.

\section{Coleta de dados}

O estudo foi realizado por meio de pesquisa em acervo bibliográfico, além de entrevista e visitas in loco ao aterro controlado e repartições mantidas pelo setor público, por parte da secretaria de Meio Ambiente e Recursos Renováveis da cidade de Corrente, Piauí, obedecendo as seguintes etapas:

\section{Revisão bibliográfica}

Objetivando um melhor entendimento, explanação e aprofundamento sobre a temática da logística reversa e sua aplicação no setor público, realizou-se primeiramente, uma pesquisa bibliográfica.

Tal pesquisa teve como norte a importância da efetivação de uma educação ambiental que objetive o aperfeiçoamento e disseminação da prática da logística reversa, principalmente no setor público.

O aprofundamento bibliográfico permeou durante todo o estudo, sempre em que surgiam termos relevantes a serem investigados conceitualmente. Foi feito tanto por meio digital, quanto em acervo de livros.

\section{Coleta de campo}


Concomitantemente à revisão bibliográfica, a segunda etapa de estudo foi através de visitas in loco:

- Á Prefeitura Municipal de Corrente e suas repartições, visando um entendimento de como a política de reversibilidade funciona no município e em que aspecto o órgão público municipal auxilia nesse processo. Realizou-se uma entrevista com os gestores municipais da Secretaria de Meio Ambiente e Recursos Renováveis da cidade;

- Ao aterro controlado, objetivando perceber como os resíduos da população correntina são alocados após sua coleta. Também, como forma de comprovar o que foi respondido nas questões da entrevista, optou-se por realizar visita de cunho observativo ao aterro.

A entrevista realizada consistiu em um bloco de perguntas abertas com o intuito de incitar um pequeno debate sobre a problemática.

Primeiro, questionou-se aos gestores se a comissão tinha conhecimento sobre a logística reversa e sua importância para a redução do acúmulo de resíduos da cidade.

Logo, foi perguntado se haviam locais em que a logística reversa é realizada no município, tanto em empresas privadas como também, na própria prefeitura e repartições em que ela administra.

O que implicou em outra questão, que diz respeito aos obstáculos enfrentados pelo setor público ao implantar essa prática na cidade de Corrente. Qual o grau de dificuldade enfrentado pelos gestores ao explicar à população como a reversibilidade dos materiais funciona e em que contribui para a sustentabilidade ambiental foram itens debatidos através desta pergunta.

Assim, quanto às possíveis práticas ambientais a serem realizadas, perguntou-se se havia alguma em planejamento e/ou execução ativa, ou em outras palavras, se existe métodos de educação ambiental aplicado à população. Pois, é primordial que a comunidade urbana e rural saiba que devem devolver determinados materiais aos seus devidos fabricantes.

Através da realização da entrevista, se impôs necessária uma visita ao aterro controlado da cidade, para comprovar e evidenciar algumas das questões e obstáculos impostos pelos gestores, itens observados após a consumação da entrevista.

\section{RESULTADOS E DISCUSSÕES}




\section{Revisão bibliográfica sobre o tema}

Pensar em logística reversa significa pensar na importância do meio ambiente para o ciclo de vida humano. Os impactos causados pela má organização lógica do processo de coleta, armazenamento e destinação são enormes frente à necessidade que se tem atualmente, de um mundo equilibrado. Em outras palavras,

A problemática ambiental reflete a percepção de que o volume de impactos destrutivos gerados pela ação antrópica sobre os ecossistemas tem-se ampliado a horizontes de longo prazo, de modo a repensar as atuais formas de desenvolvimento, tanto capitalistas como socialistas, favorecendo uma internalização efetiva do Meio Ambiente $\left(\mathrm{SAMPAIO}^{7}\right)$.

Conforme proposto por Sampaio, deve-se ter uma preocupação permanente com o ambiente. É dito que a ação do homem transformou e originou uma série de impactos na natureza e cuja qual permeará por bastante tempo.

Mas, outro ponto é importante ser lembrado: a ausência de ação humana ao reverter essa situação. Pois o ser humano tende a somente retirar materiais dos quais precisa da natureza, produzir produtos e estes, depois de comercializados, retornam ao meio de qualquer forma, muitas vezes sem passar por processos de reciclagem e/ou reversibilidade. É somente a natureza a principal fonte em que o homem utiliza para evoluir e ao passo em que a usa e não a protege, está acabando por se destruir.

Sempre estiveram em jogo, nos diversos modos de produção surgidos ao longo da história, o como produzir e o para quem destinar os frutos da produção, uma vez que a questão de onde retirar a matéria-prima necessária teve sempre uma única resposta: da natureza $\left(\mathrm{LAGO}^{8}\right)$.

O crescente avanço tecnológico deveria também fazer progredir alguns pensamentos da sociedade já que tem função evolutiva. Mas, ao invés de incitar a prática de técnicas que reduzem o acúmulo de resíduos no meio ambiente, não o faz. Isso porque ainda é escassa a consciência de uma educação ambiental na população.

Do mesmo modo, a implantação da logística reversa em algumas empresas não é eficaz, pois não há essa preocupação com a problemática ambiental. É como se esse problema fosse tido como uma questão a ser tratada no futuro e não cabe geração atual resolvê-la. O que é totalmente

\footnotetext{
7 SAMPAIO, C. A. C. Planejamento para o desenvolvimento sustentável: um estudo de caso e comparativo de municípios. Meio Ambiente \& Desenvolvimento Sustentável. n. 1. Florianópolis: Bernúncia, 2002. p. 50.

8 LAGO, A.; PÁDUA, J. A. O que é ecologia. São Paulo: Brasiliense, 1984.
} 
errado, já que conforme abordado pelo filósofo JONAS": “quanto mais se pressente o perigo do futuro, mais temos que agir no presente". E, portanto,

\begin{abstract}
A situação ideal seria que todas as pessoas, instituições e sociedades em geral pudessem ter consciência disso atuando de forma imediata e espontânea em benefício de uma economia estável, de uma sociedade justa e de um meio ambiente sustentável. Mas, por inúmeros motivos de diferentes naturezas, a maioria das pessoas ainda não está disponível e preparada para esse tipo de valores e atitudes rumo a uma consciência coletiva visando o desencadeamento de um novo processo de desenvolvimento $\left(\right.$ BRAUN $\left.^{10}\right)$.
\end{abstract}

Faz-se urgente a construção e efetivação da consciência coletiva que o autor salienta, devido os impactos do homem sobre o meio em que vive. Então, edificar um ambiente sustentável amparado por valores e ações marais. É um posicionamento necessário que, remete a uma visão holística do mundo, mas ainda há obstáculos, tendo em vista, o egoísmo humano e a obsolescência programada imposta pela indústria mercadológica.

\title{
A APLICAÇÃO DA LOGÍSTICA REVERSA NO MUNICÍPIO DE CORRENTE-PI
}

A abordagem que se almeja realizar parte do princípio de que

Todos têm direito ao meio ambiente ecologicamente equilibrado, bem de uso comum do povo e essencial à sadia qualidade de vida, impondo-se ao Poder Público e à coletividade o dever de defendê-lo e preservá-lo para as presentes e futuras gerações (BRASIL ${ }^{11}$ ).

Desse modo, a implantação da logística reversa em ambientes públicos pode vir a ser um fator de geração de renda, o que impulsiona a geração de capital local. E ainda, influencia na percepção perante a população, de como o setor público tem responsabilidade ambiental.

Observou-se através de entrevista, que os gestores da cidade analisada apesar de terem conhecimento sobre o processo de funcionamento da logística reversa, permeiam entre obstáculos diversos que por muitas vezes os impossibilitam de realizar algumas atividades, como a ausência de apoio e conhecimento da própria população, que em sua maioria, desconhece a

\footnotetext{
9 JONAS, H. O princípio responsabilidade: ensaio de uma ética para a civilização tecnológica. Rio de Janeiro: Contraponto, 2006.

${ }^{10}$ BRAUN, R. Novos Paradigmas Ambientais: Desenvolvimento ao ponto sustentável. 2. ed. atual. Petrópolis, RJ: Vozes, 2005. p. 11.

${ }^{11}$ BRASIL. Constituição (1988). Lex: Constituição [da] República Federativa do Brasil. Brasília, DF, Senado Federal, 1988. Disponível em: <http://www.planalto.gov.br/ccivil_03/Constituicao/Constituicao.htm>. Acesso em: 30/04/2015.
} 
função de um meio ambiente agradável. Dentre as atividades que são desconhecidas pela comunidade, está a logística reversa.

Foi percebido através de visita in loco, que o descarte de materiais perigosos na cidade é realizado separadamente em vazadouro à céu aberto, numa área distante da zona urbana municipal. Essa forma de alocação, considerada como uma solução rápida para o problema da destinação consiste em uma técnica usada pelos municípios para dar resposta para a grande quantidade de resíduos gerada e que devido a sua tamanha grandeza, não consegue ser tratada.

Porém, estes materiais não são incinerados e resíduos como pilhas e pneus não retornam aos seus fabricantes, como deve ocorrer com a logística reversa. Isso tem ocorrido pela falta de auxílio de pessoas capacitadas ao separar os resíduos destinados a tal processo. E juntamente a isso, a população, que mostra desconhecer como o processo funciona e sua importância, não cobra pelo recolhimento destes produtos.

Paralelamente a isso, na Prefeitura Municipal da cidade e em outras repartições cujas quais são monitoradas pelo setor público, realiza-se a reutilização materiais como papel. Os papéis já usados são reutilizados na forma de bloco de anotações, como uma maneira de minimizar a quantidade de papéis que antes, provavelmente iram para o lixo.

Apesar de não possuir o processo em si sendo praticado, um mecanismo de aplicação da logística reversa no município já está em fase de implantação. Estão sendo realizadas palestras nas escolas públicas municipais e particulares, promovidas pela Prefeitura Municipal de Corrente e supervisionadas pela comissão de Meio Ambiente e Recursos Renováveis da Prefeitura. Estas atividades tem o intuito de orientar e fomentar a ideia de separação caseira dos resíduos.

O público consiste em alunos, professores e servidores dos estabelecimentos escolares, que aprendem também sobre a importância que a logística reversa tem nos âmbitos ambiental, econômico e social. Pois, à medida que alguns produtos se tornam obsoletos, devem retornar à sua origem, para que se possa descartá-los de forma adequada.

Assim, a população começa a se conscientizar entendendo que objetos como aparelhos celulares, pneus e frascos de produtos de beleza, por exemplo, podem ser depositados em alocações corretas nos postos de recolhimento, para ser realizado pela empresa responsável, o processo reverso.

\section{CONSIDERAÇÕES FINAIS}

Com o passar do tempo, muitos produtos podem vir a se tornar obsoletos, por estarem danificados e/ou não funcionarem conforme deveriam. Então, estes devem retornar ao seu local 
de origem, ou seja, ao seu fabricante, para que ele os descarte de forma adequada ou o reaproveite em sua produção posterior.

A elaboração do presente estudo, bem como sua temática, implicou a concluir que o reaproveitamento dos resíduos sólidos contribui para a redução de impactos. Pois, medidas produzidas por empresas que gerenciem os resíduos sólidos são fundamentais para minimizar ou até mesmo, eliminar os impactos gerados sobre o meio ambiente.

O uso da logística reversa reduz a quantidade de dejetos que serão coletados e assim, diminui consequentemente, a quantidade a ser depositada no aterro. Dessa forma, depois da entrevista com os gestores ambientais da Prefeitura Municipal de Corrente foi percebido que a cidade enfrenta dificuldades ao implementar a logística reversa.

Isso se dá principalmente pela falta de conhecimento das empresas e da população Correntina, que inviabiliza o sucesso dessa prática no município. Apesar disso, são feitas por parte da Secretaria de Meio Ambiente e Recursos Renováveis, pequenas palestras com o objetivo de aperfeiçoar a ideia de educação ambiental.

\section{REFERÊNCIAS}

BRASIL. Lei n 12.305 , de 2 de agosto de 2010. Institui a Política Nacional de Resíduos Sólidos; altera a Lei no 9.605, de 12 de fevereiro de 1988; e dá outras providências. Lex: Diário Oficial [da] República Federativa do Brasil. Brasília, DF, 2010. Disponível em: < http://www.planalto.gov.br/ccivil_03/_ato2007-2010/2010/lei/112305.htm>. Acesso em: 30 de abril de 2015.

BRASIL. Constituição (1988). Lex: Constituição [da] República Federativa do Brasil. Brasília, DF, Senado Federal, $1988 . \quad$ Disponível em: $<$ http://www.planalto.gov.br/ccivil_03/Constituicao/Constituicao.htm>. Acesso em: 30 de abril de 2015.

BRAUN, R. Novos Paradigmas Ambientais: Desenvolvimento ao ponto sustentável. 2. ed. atual. Petrópolis, RJ: Vozes, 2005. p. 11. 
DAHER, C. E.; SILVA, E. P. La S.; FONSECA, A. P. Logística reversa: oportunidade para redução de custos através do gerenciamento da cadeia integrada de valor. Disponível em: <http://www.intercostos.org/documentos/081.pdf>. Acesso em: 14 de dezembro de 2014.

IBGE. Informações Estatísticas. Fundação Instituto Brasileiro de Geografia e Estatística, dados referentes ao município de Corrente-PI. IBGE, 2014. Disponível em: < http:// cidades.ibge.gov.br/xtras/perfil.php?lang=\&codmun=220290\&search $=||$ infogr $\%$ E1 fico s:-informa $\%$ E7\%F5es-completas>. Acesso em: 01 de maio de 2015.

GUARNIERI, P. Logística Reversa: em busca do equilíbrio econômico e ambiental. Recife: Clube de Autores, 2011. p. 32.

JONAS, H. O princípio responsabilidade: ensaio de uma ética para a civilização tecnológica. Rio de Janeiro: Contraponto, 2006.

LAGO, A.; PÁDUA, J. A. O que é ecologia. São Paulo: Brasiliense, 1984.

LEITE, P. R. Logística Reversa: Meio Ambiente e Competitividade. São Paulo: Pearson Prentice Hall, 2003. p. 16.

SAMPAIO, C. A. C. Planejamento para o desenvolvimento sustentável: um estudo de caso e comparativo de municípios. Meio Ambiente \& Desenvolvimento Sustentável. n. 1. Florianópolis: Bernúncia, 2002. p. 50. 